to Rico, with subdivisions by city. The directory tries to bring together in one place the component libraries in a system (e.g., the public library and its branches in a given city or the various faculties and institutes of a university), but it does not do so for universities with facilities in several cities. Each entry contains the following information: name and address of library, name of librarian, number of volumes, date established, type of library (public, university, school or special), subject specialization (only one or two given), and whether or not the library exchanges publications. The fact that the data is in Spanish should cause no problem to non-Spanish readers, because there is no text other than the preface, and the terms which occur in the listings are either cognates, or may be found quickly in any Spanish-English dictionary.

The preface points out the difficulty of obtaining up-to-date information on the size of libraries and the names of their librarians, and a special note for the section devoted to Cuba warns that there is much pre-1959 information which could not be made current. This perhaps explains why some of the statistics presented are at variance with those found in other sources (e.g., The World of Learning) and those obtained in personal contact with library staffs.

Although the compilers apparently did not feel it to be a part of their task, an analysis of the data collected would have given a useful quantitative picture of Latin American libraries. For example, a count of libraries by country shows that Brazil, Argentina, Mexico, and Colombia are (as one might expect) far in the lead; each reports two hundred or more-a figure which no other nation approaches. This reader noted 126 libraries of over fifty thousand volumes each, with the ten largest being, in descending order: National Library of Brazil, National Library of Chile, General Administration of Archives, Libraries, and Museums (Chile), National Library of Argentina, Faculty of Medicine (University of Buenos Aires), the national libraries of Uruguay, Mexico, Venezuela, and Colombia, and the University of La Plata (Argentina).

That the compilers recognize the shortcomings of this directory is clearly indicated by the fact that it carries the label "pro- visional edition." This reviewer offers the following suggestions for incorporation into the final version: (1) coverage on a more uniform basis of such types of libraries as those of university faculties and institutes and those of the bi-national centers; (2) expansion of listings to include the newly independent nations of the Caribbean and the remaining European possessions in the area, thus making the directory comprehensive for the entire area south of the Rio Grande; (3) enlarging the data on each library to include size of staff, budget, volumes circulated and possibly publications issued; (4) analysis, perhaps in an introductory section, of the information presented; and (5) preparation of an index of names of libraries and librarians and of the subject specialties indicated. Perhaps this is too much to expect from the limited staff of the Library Development Program without outside assistance from a university or foundation, but the problem might be attacked over a period of time by dividing the compilation into several regional volumes or even separate directories for each type of library.

There is no doubt, however, that until a replacement for this provisional edition appears, it will serve not only as a useful directory but also as a guide to potential exchange sources among libraries in the Americas.-William Vernon Jackson, University of Wisconsin.

\section{Information Retrieval}

\section{Nonconventional Technical Information} Systems in Current Use. No. 3. Washington, D.C.: National Science Foundation, October 1962. xx, 209p.

In January of 1958, the National Science Foundation published a slender pamphlet of forty-three pages under the title Nonconventional Technical Information Systems in Current Use. This compilation, prepared by Madeline Berry (now Mrs. Henderson) of the NSF Scientific Documentation Program, described twenty-four "technical information systems, currently in operation, embodying new principles for the organization of subject matter or employing automatic equipment for storage and search." 
These systems were manual or mechanized and employed aspect cards or item cards. Five of the systems described were in use at government installations (National Institutes of Health, Naval Ordnance Test Station, U.S. Army Biological Warfare Laboratory, U.S. Geological Survey, and U.S. Patent Office), and all others were in large industrial organizations.

A second edition, listing thirty-four systems, appeared in September of 1959, by which time two universities (Purdue and the University of Illinois) had joined the ranks of the innovators. A supplement to the second edition, listing eighteen new systems (including a personal file at Wayne State University), was published in March 1960.

The third edition, which appeared in October of 1962, demonstrates the dramatic growth in numbers of nonconventional information retrieval systems in an astonishingly short period of time. The present volume contains 209 pages, a five-fold increase over the first edition, and describes almost ninety systems. Industry still leads in the use of these systems, fifty-one being in industrial organizations; of these chemicals are the largest single group, though pharmaceuticals and electronics are well represented. The greatest expansion, however, seems to have taken place in the agencies of the federal government, represented by eighteen installations, almost a four-fold increase since 1958. Universities still lag, though their ranks have been augmented by the addition of Montreal, Pittsburgh, and Western Reserve. A few independent research organizations (such as Battelle Memorial Institute) have also begun the use of nonconventional information systems.

Increasing sophistication in such systems is also evident in the variety of principles now employed in their construction and the techniques applied in their use. The original simple classification devised by Mrs. Henderson is no longer adequate, and the third edition is arranged as follows:

1. Systems which store references (57)

Manual (2)

Uniterm (7)

Peek-a-Boo (7)

Edge-notched cards (3)

Simple sorter (14)
Collative (12)

Photographic (2)

Computer (10)

2. Systems which store data (17)

Chemical-biological test data (11)

Administrative data (2)

Other data (4)

3. Systems which produce general search aids (15)

Indexes, bibliographies, and publication aids (9)

Machine-searchable files (4)

The usefulness of this volume is increased by the inclusion of three appendices which are, respectively, a supplementary guide to individuals and organizations of which the systems are described in the body of the text; an index of geographical locations (the District of Columbia leads with twelve entries, while Ohio and New Jersey rank next with eight each); and a "subject guide." A preliminary section also provides useful definitions and scope notes to the classification of the entries.

Despite the fact that this publication is not evaluative, and that the descriptions submitted are only edited, not verified, as the first ones were, as a general inventory the compilation should be useful to all who are concerned with the development of bibliographic and information systems, conventional and otherwise. The Office of Science Information Service of the National Science Foundation is to be commended for making this material available at frequent intervals.

Assuming the accuracy and completeness of this list, a number of important and interesting observations can be made respecting the emergence of nonconventional systems for the organization of information. The rapid proliferation is obvious, and the increasing sophistication has already been mentioned. Moreover, one may assume that they are proving to be successful, since of the total listed only six have been abandoned, and one of these was eliminated by a corporate merger. As noted above, industry has taken the lead in developing these systems, and chemicals would seem to be most acutely aware of the need for improvement in access to recorded information. Substantially more than half of the systems inventoried store references rather than sub- 
stantive data, which fact tends to substantiate the contention of R. A. Fairthorne that, in most instances, "information retrieval" really means "document retrieval," and in the final analysis, much of the work in so-called information retrieval has really been the invention of mechanical stack-boys.

Librarians in general, and those engaged in library education in particular, can find small reason for pride in this volume. Innovation in information systems is definitely not coming from the library world, and only one library school is listed in this compilation. Admittedly, such a catalog as is here reviewed can throw no light on the extent to which these unconventional systems represent a real advance over traditional library methods, but there seems to be little basis for believing that this trend toward the unconventional will not become an important force in the librarianship of the future. If librarians continue in their neglect of it, they may one day find themselves hopelessly outdistanced in the race to surmount the rising Everest of man's recorded knowledge.-J. H. Shera, Western Reserve University.

Information Retrieval Management. Ed. by Lowell H. Hattery and Edward M. McCormick. Detroit: American Data Processing, 1962. $151 \mathrm{p} . \$ 15$.

This is a potpourri of papers, adapted from the proceedings of the Fourth Institute on Information Storage and Retrieval presented in February 1962 at American University. As with all such stews, some of the meat is tender and tasty, most of the vegetables are either underdone or so paplike as to inhibit taste, and one's favorite ingredient is either absent or illcooked. Such collections are becoming all too frequent. At least five such volumes on various aspects of the information sciences have appeared in the winter and spring of 196263. These potpourries may have stimulating paragraphs or even whole papers. As books, however, they suffer from discontinuity, hastily presented ideas with little supporting evidence, and advice reminiscent of commencement addresses. Above all, they illustrate the paucity of our knowledge, both empirical and pragmatic, of information systems.

The volume at hand is no exception. According to the editors, the purpose of the papers is "to present a broader systems approach to the handling of technical information." (This reviewer can't find the referent to "broader" in the Preface.) Of the eighteen papers in the volume, only nine seem to fit the "systems approach." (Perhaps this is the meaning of "broader.") This does not mean the other papers are poor. In fact, the better papers appear outside the "systems approach."

The papers can be divided (although they are not physically so divided) into five general categories. The first explores cultural and intellectual aspects, and exhorts the reader to do something under such titles as "What Must Give in the Documentation Crisis." However, one should not miss Saul Gorn's paper "Computers, Communication and Science-Extending Man's Intellect," a perceptive tour de force on "computer appreciation."

The second subject area examines management's relations to information centers. Edward McCormick's paper, the last in the volume, is a good summary. In fact, it should be read first.

In the third area, the papers explore facets of communication. H. P. Luhn, as usual, writes well on "Automated Intelligence Systems." Helen Brownson reviews the state of knowledge of the communication habits of scientists-a state, and Mrs. Brownson agrees, largely unknown and unexplored. As Don Swanson so aptly put it, past studies have been "descriptive rather than diagnostic."

In the fourth category, three papers skim rapidly over various approaches to information management. In one paper, by C. D. Gull, the reader is urged to answer such questions as "Is our present system satisfactory?" without a clue as to what a "satisfactory" system is.

The final three papers describe the operating experience of three information centers-Esso Research and Engineering, General Electric Flight Propulsion Division, and the Science and Technology Division of the Library of Congress.

This volume, like others of the genera, is significant in its intimations of a future in 